\title{
Reseña
}

\section{Alejandro Korn. Lecciones de histórica de la filosofía c. 1918}

\author{
(Transcripción y primera edición por Clara Alicia Jalif de \\ Bertranou; introducción por Juan Carlos Torchia Estrada. \\ Cuyo (Argentina): Instituto de Filosofía Argentina y Americana, \\ Universidad Nacional de Cuyo, 2011, 406 páginas)
}

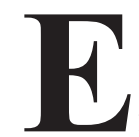
sta publicación comprende las 34 lecciones impartidas magistralmente -en su sentido literal- pro el Dr. Alejandro Korn (Argentina, 18601936) en 1918 en la Facultad de Filosofía y Letras de la Universidad de Buenos Aires, en el curso de Historia de la Filosofía. Desde la primera lección, Korn explica por qué se trata de un curso de historia de la filosofía y no un curso de filosofía, dos cosas muy diferentes, mientras compara con una clase de física donde se aprende esta disciplina pero no su historia.

El magisterio filosófico de Korn se caracteriza por su capacidad de diálogo y la generación de reflexión entre el joven alumnado. Como resultado tenemos este documento que representa la preocupación por recuperar documentos de la historia, así como de la educación y la cultura argentina. También, la obra aporta al estudio de la producción escrita de Korn y permite establecer comparaciones con esta respecto a su pensamiento. Por la fecha de estas lecciones, se desprende que es el periodo en que predominaba el positivismo en Argentina y en América Latina.

En un tema más coloquial que crudito, Korn transmite en forma didáctica sobre la base de cuatro ejes fundamentales: ontología, conocimiento, ética y estética. La necesidad de la tolerancia que propugna y a la autosuficiencia: “(p.23). Sus lecciones no se comparan con ninguna fuente histórica que pudiera haber en esa época y que le sirviera de sustento.

Concluye Forchia Estrada: “...venimos así a descubrir, en el curso elemental de historia de la filosofía, la veta de pensamiento más honda, la aspiración más alta del filósofo Alejandro Korn" (p.40). 
